\title{
Calciphylaxis: Do Calcimimetics Have a Role in Management?
}

\author{
Arif Mutwali*, Khairi Muhammad, George Mellotte, Donal Reddan \\ University College Hospital, Galway, Ireland
}

\begin{abstract}
Introduction: Calciphylaxis is a rare but serious systemic disorder characterized by small vessel calcification leading to tissue ischemia. Abnormalities in mineral metabolism that are often associated with uremia are important predisposing factors. The optimal therapy for calciphylaxis is prevention through rigorous control of phosphate and calcium balance. We here present two cases of calciphylaxis that responded to an intensive treatment protocol based on cinacalcet.
\end{abstract}

Case 1: The first patient was a 60-year old lady who was on regular hemodialysis for two years. She presented with four months history of painful, necrotic, non-healing ulcers on her right leg despite intact peripheral pluses. Her calcium level was $11.6 \mathrm{mg} / \mathrm{dl}$, phosphate $6.6 \mathrm{mg} / \mathrm{dl}$ and parathyroid hormone (PTH) $1450 \mathrm{pg} / \mathrm{ml}$. The diagnosis of calciphylaxis was confirmed by ulcer punch biopsy. The patient was treated with cinacalcet $90 \mathrm{mg}$ daily, increasing the dose of non-calcium based phosphate binders, lowcalcium dialysate, and withdrawal of alfacalcidol. At the end of six months of this therapy, the ulcers almost healed and renal bone profile normalized.

Case 2: The second patient was a 58-year old gentleman with advanced chronic allograft nephropathy. He presented with painful, non healing ulcers on his calf. His calcium level was $12.4 \mathrm{mg} / \mathrm{dl}$, phosphate $5.9 \mathrm{mg} / \mathrm{dl}$ and PTH 1009 pg/ml and he had recently stopped using alphacalcidol. He was treated with cinacalcet $90 \mathrm{mg}$ daily and increasing the dose of non-calcium based phosphate binders. Within three months, his renal bone profile was within target levels and his ulcers had significantly improved.

Conclusion: Calcimimetics have a potential role in the treatment of calciphylaxis, as demonstrated by these two cases.

\footnotetext{
* Corresponding author; E mail: amutwali@hotmail.com
}

Keywords: Calcimimetics; Calciphylaxis; Cinacalcet

\section{The authors declared no conflict of interest}

\section{Introduction}

Calciphylaxis is a rare but serious disorder characterized by systemic medial calcification of the arteries that was first described in 1962. Unlike other forms of vascular calcifications, calciphylaxis is characterized by small vessel mural calcification with or without endovascular fibrosis, extravascular calcification and vascular thrombosis, leading to tissue ischemia [1].

Calciphylaxis most commonly occurs in patients with end-stage renal disease (ESRD) who are on hemodialysis (HD) or who have recently received renal transplantation $[2,3]$. However, it does not exclusively occur in ESRD patients [4-9]. Its incidence appears to be increasing due in part to the practice of treating severe hyperparathyroidism with calcium-based phosphate binders and vitamin D analogs [10]. A cross sectional study of $242 \mathrm{HD}$ patients in an outpatient unit revealed a prevalence of 4\% [11].

The pathogenesis of calciphylaxis is poorly understood. Abnormalities in mineral metabolism that predispose to vascular and soft tissue calcification in uremia are clearly involved [10], but no single abnormality is sufficient to predict the development of this disorder. For reasons that are unclear, additional factors are involved in calciphylaxis. Possible mechanisms to account for the more severe reduction in blood flow are intimal fibrosis associated with the calcifications, massive mural calcifications of the dermohypodermic arterioles, and thrombus formation within the venules [1].

Hyperparathyroidism, vitamin D supplementation, hyperphosphatemia, and an elevated or normal plasma calcium concentration all play a role in calciphylaxis [1, 12]. However, these factors are commonly present in ESRD and none is sufficient to explain why calciphylaxis is so rare. A role for parathyroid hormone is supported by the reported clinical improvement following parathyroidectomy and by the ability to experimentally 
induce ischemic skin necrosis in animals via excess administration of PTH. However, most patients with severe hyperparathyroidism do not have skin necrosis. In two studies consisting of 25 dialysis patients with the disorder, other significant risk factors were found to be white race, morbid obesity, recent severe weight loss, administration of warfarin, and low serum concentrations of albumin [13, 14].

The optimal therapy for calciphylaxis is prevention through rigorous control of phosphate and calcium balance. Calcimimetics are agents that allosterically increase the sensitivity of the calcium-sensing receptor (CaSR) in the parathyroid gland to calcium [15]. The CaSR is the principal factor regulating parathyroid gland PTH secretion and hyperplasia. The separate target offers the potential to suppress PTH by mechanisms complementary and potentially synergistic with vitamin $\mathrm{D}$ analogues. Cinacalcet is currently the only available calcimimetic. We here present two cases of calciphylaxis that responded to an intensive treatment protocol based on cinacalcet.

\section{Case series}

\section{Case 1}

Our first patient was a 60-year old lady with ESRD due to diabetic nephropathy. She had been on regular HD for two years preceded by another two years on peritoneal dialysis. She presented with four months history of painful non healing ulcers on her right leg.The ulcers were necrotic in appearance despite intact peripheral pluses. She had good ulcer care and reasonably controlled diabetes; however, her ulcers were still not healing.

Her hemoglobin was $11.6 \mathrm{~g} / \mathrm{dl}$, calcium $11.6 \mathrm{mg} / \mathrm{dl}$, phosphate $6.6 \mathrm{mg} / \mathrm{dl}$, parathyroid hormon (PTH) 1450 $\mathrm{pg} / \mathrm{ml}$, albumin $3.4 \mathrm{~g} / \mathrm{dl}$ and Kt/V 1.03. Her medications included sevelamer $1600 \mathrm{mg}$ TDS and alfacalcidol 0.75 mcg daily. A clinical diagnosis of calciphylaxis was made and confirmed by ulcer punch biopsy. The patient was started on cinacalcet $30 \mathrm{mg}$ daily and advised to increase her non-calcium based phosphate binders. Cinacalcet dose was later titrated up to $90 \mathrm{mg}$ daily. Low calcium dialysate was used and alfacalcidol was held. She was also offered appropriate dietary advice, aggressive ulcers care, and adequate pain control. The ulcers healed almost completely within 6 month of this therapy. Her renal bone profile by then revealed a calcium level of $9.4 \mathrm{mg} /$ dl, phosphorus $4.4 \mathrm{mg} / \mathrm{dl}$ and PTH 450 pg/ml.

\section{Case 2}

The second patient was a 58-year old gentleman with advanced chronic allograft nephropathy at 12-year post transplantation. His primary renal disease was hypertensive nephrocalcinosis and he was not diabetic. He presented with painful, non healing ulcers on his calf. The ulcers were tender and very necrotic in appearance with intact peripheral pulses (Figure 1). His serum creatinine was $4.4 \mathrm{mg} / \mathrm{dl}$ with an estimated glomerular filtration rate of $16 \mathrm{ml} / \mathrm{min}$. His hemoglobin was $10 \mathrm{~g} / \mathrm{dl}$, calcium $12.4 \mathrm{mg} / \mathrm{dl}$, phosphate $5.9 \mathrm{mg} / \mathrm{dl}$, albumin $3.7 \mathrm{~g} / \mathrm{dl}$ and PTH 1009 pg/ml. He was using sevelamer $800 \mathrm{mg}$ TDS as phosphate binder and his alphacalcidol was recently stopped.

A clinical diagnosis of calciphylaxis was made based on his renal bone profile and the ulcers morphology. He was managed with aggressive ulcer care and analgesia to control the pain. He was commenced on cinacalcet 30 mg daily titrated later up to $90 \mathrm{mg}$ daily. His phosphate binders were increased along with appropriate dietary advice. Within three months of this management, his renal bone profile was within target limits, he was pain free, and his ulcers had significantly improved (Figure 2).

\section{Discussion}

The occurrence of calciphylaxis is frequently precipitated by a specific event, such as local skin trauma and/or injections. Such a precipitant was not evident in these two patients. Calciphylaxis is typically characterized by areas of ischemic necrosis that usually develop in the dermis, subcutaneous fat, and less often in muscle. These ischemic changes lead to livedo reticularis, painful, plaque-like subcutaneous nodules on the trunk, buttocks or proximal extremity, which are areas of greatest adiposity [2]. The initially noted purpuric plaques and nodules subsequently progress to ischemic/necrotic ulcers that often become super infected. Infection has a grave impact on prognosis [10], and its absence may have contributed to the favourable response to therapy in these two patients. There is no diagnostic laboratory test for calciphylaxis. High plasma levels of PTH, phosphate, and calcium and a positive bone scan are consistent with the diagnosis, but all of these abnormalities are not always present $[4,6]$. Bone scintigraphy is not routinely utilized as a diagnostic tool, but noninvasive imaging modality can aid in both diagnosing the disease and monitoring its progression. The diagnosis of calciphylaxis is usually suggested by the characteristic ischemic skin lesions. It is then confirmed by skin biopsy which shows arterial occlusion and calcification in the absence of vasculitic change [16]. The most common pathologic finding in both early and late stage cases is acute and chronic calcifying septal panniculitis [16].

Given the high mortality associated with calciphylaxis, early recognition and treatment are essential. The optimal 
Figure 1: Calciphylaxis ulcers on the second patient's calf at presentation

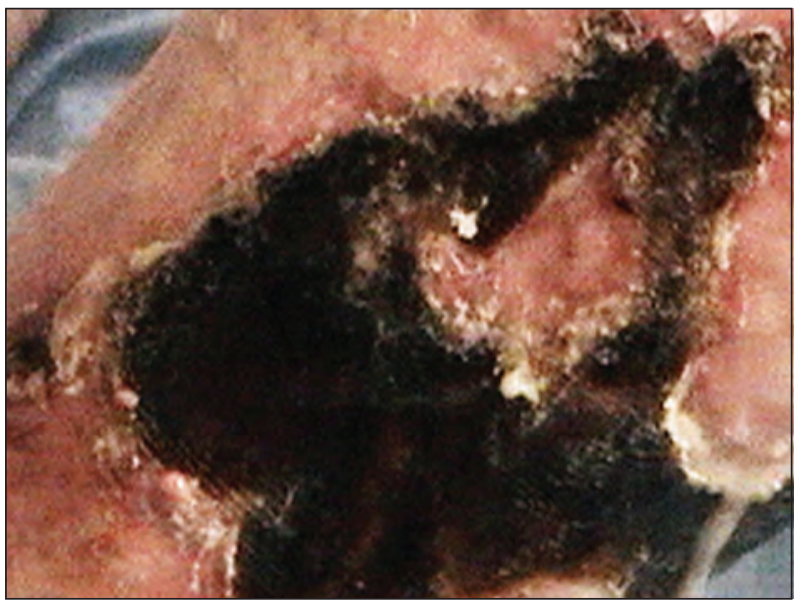

therapy is prevention. Rigorous control of phosphate and calcium balance should avoid the metabolic milieu in which calciphylaxis may occur. There are no controlled studies for the treatment of established calciphylaxis, and specific therapeutic regimens have been limited to isolated cases.

A reasonable plan of intervention should include an aggressive program of wound care, adequate pain control, and correction of underlying abnormalities in plasma calcium and phosphorus concentration. This includes cessation of vitamin D supplementation, the use of low-calcium dialysate and non-calcium based rather than calcium-based phosphate binders for the treatment of hyperphosphatemia. Avoidance of local tissue trauma, including subcutaneous injections and transfusion of blood products, is also important.

The role of urgent parathyroidectomy is uncertain even in calciphylaxis associated with frank hyperparathyroidism. Surgical series suffer from selection bias and small numbers of patients [17, 18]. A number of novel and experimental therapies have been evaluated in calciphylaxis. In an experimental model, administration of bisphosphonate inhibited calciphylactic reaction in rats treated with sub-lethal doses of vitamin D [19]. In addition, six doses of intravenous pamidronate therapy were reported to resolve the calciphylaxis lesions in a chronic renal failure patient [20]. In a series of five patients, hyperbaric oxygen therapy consisting of 25-35 ninety-minutes sessions at 2.5 atmospheres resulted in complete healing of extensive necrotic ulcers in two individuals while lesions did not respond in the remaining three patients [21]. Prednisolone is another potential therapeutic agent. In a single center study, prednisolone resulted in stabilization or improvement in eleven out of fourteen patients with non-ulcerating calciphylaxis
Figure 2: Appearance of the second patient's ulcer after three months of therapy

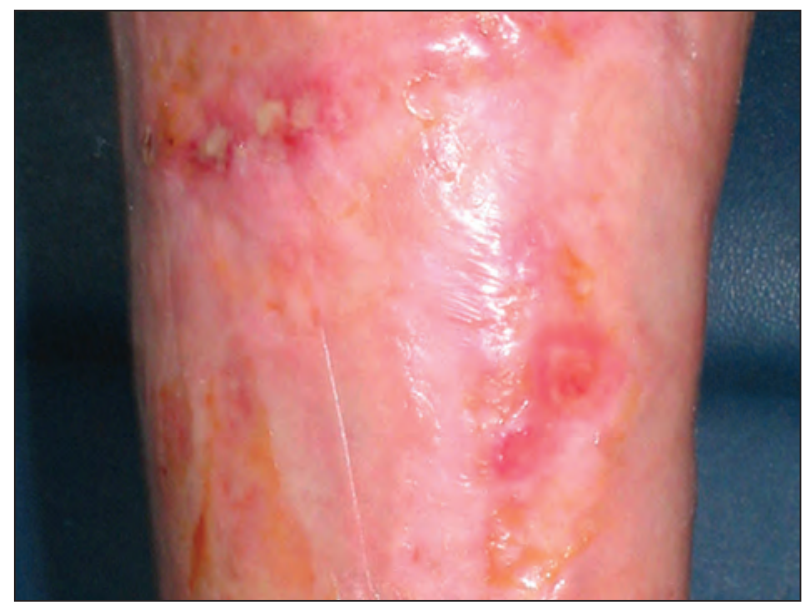

plaques. However, given the lack of an adequate control group and the marked infection risk associated with corticosteroids use, further studies are clearly needed to evaluate the role, if any, of corticosteroids in this setting [10]. In another two case reports, intravenous sodium thiosulfate given either three or four times per week successfully relieved the signs and symptoms of calciphylaxis $[22,23]$. Success in another patient was also reported with the combination of intravenous sodium thiosulfate and continuous venovenous hemofiltration with low calcium replacement fluids [24]. The response of calciphylaxis to any therapeutic regimen is never assured and the prognosis remains poor [10]. Features that negatively impact on prognosis include more advanced disease at the time of therapy as well as the presence of proximal ischemic and necrotic lesions in the skin and soft tissues [10]. Infection is the primary cause of high mortality associated with this condition, up to $80 \%$ in one report. [10]

There are few reports of successful management of calciphylaxis by using cincalcet in the literature [25-28]. The potential role of calcimimetics in the treatment of calciphylaxis, as demonstrated by these two reported cases, warrants further studies. This would simplify the management of a serious condition without the need to resort to invasive measures such as parathyroidectomy.

\section{Conclusion}

Calcimimetic therapy may have a beneficial role in inducing ulcer healing in patients with calciphylaxis. 


\section{References}

1. Adrogué HJ, Frazier MR, Zeluff B, Suki WN. Systemic calciphylaxis revisited. Am J Nephrol. 1981;1(3-4):17783.

2. DT Janigan, DJ Hirsch, GA Klassen, AS MacDonald. Calcified subcutaneous arterioles with infarcts of the subcutis and skin «calciphylaxis» in chronic renal failure. Am J Kidney Dis. 2000 Apr;35(4):588-97.

3. LJ Perloff, RK Spence, RA Grossman, CF Barker. Lethal post-transplantation calcinosis. Transplantation. 1979 Jan;27(1):21-5.

4. Kalajian AH, Malhotra PS, Callen JP, Parker LP. Calciphylaxis with normal renal and parathyroid function: not as rare as previously believed. Arch Dermatol. 2009 Apr;145(4):451-8.

5. Swanson AM, Desai SR, Jackson JD, Andea AA, Hughey LC. Calciphylaxis associated with chronic inflammatory conditions, immunosuppression therapy, and normal renal function: a report of 2 cases. Arch Dermatol. 2009 Jun;145(6):723-5.

6. Banky JP, Dowling JP, Miles C. Idiopathic calciphylaxis. Australas J Dermatol. 2002 Aug;43(3):190-3.

7. Almafragi A, Vandorpe J, Dujardin K. Calciphylaxis in a cardiac patient without renal disease. Acta Cardiol. 2009 Feb;64(1):91-3.

8. Couto FM, Chen H, Blank RD, Drezner MK. Calciphylaxis in the absence of end-stage renal disease. Endocr Pract. 2006 Jul-Aug;12(4):406-10.

9. Lim SP, Batta K, Tan BB. Calciphylaxis in a patient with alcoholic liver disease in the absence of renal failure. Clin Exp Dermatol. 2003 Jan;28(1):34-6.

10. Fine A, Zacharias J. Calciphylaxis is usually nonulcerating: risk factors, outcome and therapy. Kidney Int. 2002 Jun;61(6):2210-7.

11. Angelis M, Wong LL, Myers SA, Wong LM.Calciphylaxis in patients on hemodialysis: a prevalence study. Surgery. 1997 Dec;122(6):1083-9

12. Levin A, Mehta RL, Goldstein MB. Mathematical formulation to help identify the patient at risk of ischemic tissue necrosis: a potentially lethal complication of chronic renal failure. Am J Nephrol. 1993;13(6):448-53.

13. Bleyer AJ, Choi M, Igwemezie B, de la Torre E, White WL.A case control study of proximal calciphylaxis. Am J Kidney Dis. 1998 Sep;32(3):376-83.

14. Coates T, Kirkland GS, Dymock RB, Murphy BF, Brealey JK, Mathew TH, Disney AP.Cutaneous necrosis from calcific uremic arteriolopathy. Am J Kidney Dis. 1998 Sep;32(3):384-91.

15. Nemeth, EF, Bennett, SA. Tricking the parathyroid gland with novel calcimimetic agents (editorial). Nephrol Dial Transplant. 1998;13:1923.
16. Essary LR, Wick MR. Cutaneous calciphylaxis. An underrecognized clinicopathologic entity. Am J Clin Pathol. 2000 Feb;113(2):280-7.

17. Kang AS, McCarthy JT, Rowland C, Farley DR, van Heerden JA. Is calciphylaxis best treated surgically or medically. Surgery. 2000 Dec;128(6):967-71.

18. Girotto JA, Harmon JW, Ratner LE, Nicol TL, Wong $\mathrm{L}$, Chen $\mathrm{H}$. Parathyroidectomy promotes wound healing and prolongs survival in patients with calciphylaxis from secondary hyperparathyroidism. Surgery. 2001 Oct;130(4):645-50.

19. Price PA, Omid N, Than TN, Williamson MK. The amino bisphosphonate ibandronate prevents calciphylaxis in the rat at doses that inhibit bone resorption. Calcif Tissue Int. 2002 Oct;71(4):356-63.

20. Monney P, Nguyen QV, Perroud H, Descombes E. Rapid improvement of calciphylaxis after intravenous pamidronate therapy in a patient with chronic renal failure. Nephrol Dial Transplant. 2004 Aug;19(8):2130-2.

21. Podymow T, Wherrett C, Burns KD.Hyperbaric oxygen in the treatment of calciphylaxis: a case series. Nephrol Dial Transplant. 2001 Nov;16(11):2176-80

22. Cicone JS, Petronis JB, Embert CD, Spector DA.Successful treatment of calciphylaxis with intravenous sodium thiosulfate. Am J Kidney Dis. 2004 Jun;43(6):1104-8.

23. Brucculeri M, Cheigh J, Bauer G, Serur D. Long-term intravenous sodium thiosulfate in the treatment of a patient with calciphylaxis. Semin Dial. 2005 SepOct;18(5):431-4.

24. G Guerra, RC Shah, EA Ross. Rapid resolution of calciphylaxis with intravenous sodium thiosulfate and continuous venovenous haemofiltration using low calcium replacement fluid: case report. Nephrol Dial Transplant. 2005 Jun;20(6):1260-2.

25. Mohammed IA, Sekar V, Bubtana AJ, Mitra S, Hutchison AJ. Proximal calciphylaxis treated with calcimimetic "Cinacalcet". Nephrol Dial Transplant. 2008 Jan;23(1):387-9.

26. Velasco N, MacGregor MS, Innes A, MacKay IG. Successful treatment of calciphylaxis with cinacalcetan alternative to parathyroidectomy? Nephrol Dial Transplant. 2006 Jul;21(7):1999-2004.

27. Robinson MR, Augustine JJ, Korman NJ. Cinacalcet for the treatment of calciphylaxis. Arch Dermatol. 2007 Feb;143(2):152-4.

28. Sharma A, Burkitt-Wright E, Rustom R. Cinacalcet as an adjunct in the successful treatment of calciphylaxis. Br J Dermatol. 2006 Dec;155(6):1295-7. 